\title{
Value Research on Introduction of EAP Technology in Middle and Small- sized Enterprises in China
}

\author{
guangli LUO \\ Postdoctoral Science Research Workstation of China Industrial Safety Research Center, Beijing Jiaotong \\ University, China
}

ABSTRACT: The overall situation in middle and small-sized enterprises in China is that management level and
science quality of CEO (person in charge) are not high, with poor executive ability, while management level and
employees are relatives in most private enterprises of middle and small size. Various subjective and objective
factors have caused certain difference between domestic middle and small-sized enterprises and international
counterparts, which mainly presented in: Unsound socialization degree, poor competitive strength, and
insufficient power for participating in global distribution, makes most middle and small-sized enterprises weak in
market competition. In a big population country like China, it is crucial to make a living for people, which not
only relates to social stability and unity, but relates to macro-economy development tendency of China. Although large and middle-sized enterprises in China have undertaken most responsibilities for employment and survival, for huge population in China, people need to solve such problem still account for a great part. However, middle and small-sized enterprises have undertaken a great burden on solving the issue of employment and survival for such people. Chinese middle and small-sized enterprises plays an indispensable role in solving employment issue for most civilians. This has an immeasurable impact on social stability and economic development. Under the situation of white-hot economic competition, congenital deficiency, absence in talent and technology, and advantage difference in market competition etc., makes Chinese middle and smallsized enterprises treat on eggs. Although the country has provided certain support in policies and funds, while how to enhance the strength of middle and small-sized enterprises from the root, and to change operation thought among middle and small-sized enterprises, this is only a drop in the bucket. There's a saying in Taoism that "Delegate to fish, as delegate to fish" - to give the method for "earning money" is better than give money. The way for middle and small-sized enterprises to adapt to needs for survival and development nowadays, is to start from self-examination, independent physical fitness and spontaneous reform among middle and small-sized enterprises, so as to achieve continuous self-perfection. EAP technology is an organizational auxiliary method to help the organization improve itself and grow constantly. EAP belongs to employee assistance service field initially, now for the demand of market and enterprise, EAP has evolved into a support system focusing on enterprise's development and management, which is Organization Assistance Programs (OAP). Chinese middle and small-sized enterprises, under insufficient development strength, have obtained inner energy and cultivated comprehensive strength of themselves via external power, thus making EAP become a support and pattern of the most effective and pertinent strength. Essential characteristics of EAP: "EAP technology is a channel for the enterprise to link to external market, as well as a soft strength for inner soft development", which enables Chinese middle and small-sized enterprises to understand their disadvantages, participate into international competition and to enhance comprehensive strength.

During economic transition in China, EAP's introduction of middle and small-sized enterprises in China has a coordinate significance, so it is required to make great efforts to promote the application.

KEYWORD: Middle and Small-sized Enterprises, Weakness, EAP, Growth and Development

\section{STATUS ANALYSIS ON MIDDLE AND SMALL-SIZED ENTERPRISES IN CHINA}

Analyzing from social demand, middle and smallsized enterprises plays an irreplaceable role in economic development in China. For multiple enterprises of middle and small size, Zhang Zhigang, Vice Director of the National Economic and Trade Commission recently said that, by now, middle and small-sized enterprises in China have exceeded 8 
million, accounting for $99 \%$ of enterprises in China. However, most enterprises of middle and small size in China are founded based on original survival needs.

\section{UNIQUENSS ANALYSIS ON CHINESE MIDDLE AND SMALL-SIZED ENTERPRISES}

The uniqueness mainly reflects on pattern and operation management form generated by organization. Chinese middle and small-sized enterprises have certain particularity, despite of numerous issues explained previously, it is still related to the particularity. Particularity of an issue is closely related to the reason for its formation, just like the reason for influence on psychology is certain to relate with its original ecological family (birth environment), it is the same with Chinese middle and small-sized enterprises. Enterprises meet social needs via engaging themselves in economic activities such as production, logistics and service etc., which are legally-founded profit organizations with economic legal person's right via self-management and independent accounting. It could be seen from definition that enterprises are formed based on socialized production. Enterprises have their own properties and characteristics. Modern enterprise management system is also imported from the west. Forming environment of Chinese enterprises also transits directly from agricultural feudal society to industrial society. Without experiencing the accumulation process of bourgeois development, when compared to western enterprises, no matter from experience or other aspects, there's certain uniqueness in Chinese enterprises, as well as drawbacks in conception.

\section{ANALYSIS ON SOCIAL EFFECT AMONG CHINESE MIDDLE AND SMALL-SIZED ENTERPRISES}

Although there're still lots of issues to be improved in Chinese middle and small-sized enterprises at present, the function and value are irreplaceable, and the existence is inevitable either. Chinese middle and small-sized enterprises are good to special cultural soil and welfare via which they are living, and are playing a special bearing role in national environment and social development. Especially during the initial stage of reform and open period in China, middle and small-sized enterprises has already played an unprecedented role in Chinese social economy and employment, and many national industries and traditional secret recipe enterprises emerged, which are pioneer representatives for Chinese middle and small-sized enterprises during specific period, with pioneering spirit, showing national style and significance for specific epoch. Numerous Chinese people have changed their fate, realized their dream of fortune and their idea of making a living via operating middle and small-sized enterprises. At present, middle and small-sized enterprises accounts for more than $99 \%$ in the total enterprises in China, and related GDP accounts for $60 \%$ of the nation, while tax paid accounts for $50 \%$ of the total national tax revenue, besides, they've also provided more than $75 \%$ jobs in cities and towns. ${ }^{1}$

If middle and small-sized enterprises in China could achieve further development, this will become a powerful support for objectives such as China's asset increase, economic growth and employment etc., which acts as an economic fortress for national stability and unity as well as social undertakings. We shall appreciate the responsibilities undertaken by Chinese super tenacious middle and small-sized enterprises in social development during special time and situation in China For particularity of middle and small-sized enterprises in China, the development of middle and small-sized enterprises could promote the adjustment in China's economic structure as well as transition in economic growth method better.

Middle and small-sized enterprises are the most active groups in market economy, which is a new force in technology innovation. $65 \%$ Chinese patents, over $75 \%$ technology innovations and over $80 \%$ new product developments are all achieved by middle and small-sized enterprises. Whether such groups with huge vitality could grow well, directly relates to innovation ability of China's economy as well as to sustainable development capacity. When new times requirements have been put forward to middle and small-sized enterprises, we shall consider that: How to help middle and small-sized enterprises to keep pace with the times, and adapt to the development need for the new age? Meanwhile, it is also required to provide practical and effective solutions.

\section{IMPORTANT SIGINIFCANCE ON HEALTH DEVELOPMNENT AMONG CHINESE MIDDLE AND SMALL-SIZED ENTERPRISES VIA INTRODUCING EAP}

EAP (Employee Assistance Program), is initially paid by enterprises, which is a professional and systematic welfare project and assistance support approved by both employees and their families, so as to help them grow and realize a sound working and living status. It is to help employees and their families solve difficulties in psychology and behavior via diagnosis, suggestion, guidance, training and consultancy carried

\footnotetext{
${ }^{1}$ Preliminary Study on Improving Competitive Strength of Middle and Small-Sized Enterprises Long Xiaorong, Xu Jianping - Value Project - 2010
} 
out by experts on employees, so as to achieve the purpose of improving organizational performance and employee relationship, as well as organizing atmosphere. In a word, initially, EAP is an effective mechanism used by the enterprise to manage and solve employee's personal issues, so as to improve performance of employees and enterprises. Currently, 90\% enterprises ranking Top 500 in the world have implemented the EAP system. 25\% employees in America have enjoyed welfare support of EAP. Over decades of development, EAP's service mode and content have become complete and abundant: Pressure, psychology, family life, healthy style, legal aid, financial planning, stress events, career planning, marriage and sexual relations, eating disorder etc., have helped employees to solve in an all-round way.

This dissertation is based on the application research of EAP among Chinese middle and smallsized enterprises, hoping to provide some suggestions and opinions on how to establish and promote EAP in Chinese mode.

For Chinese middle and small-sized enterprises have their own drawbacks, plus China is still in its transitional period, social conflicts are increasing, and people are undertaking various pressures, forming heavy mental burden, and causing lots of mental patients. According to related data from the National Ministry of Health in 2005, by now, there're about 16 million mental patients in China, ranking the first in the overall burden in Chinese disease burden, accounting for about $20 \%$, besides, there's an obvious increasing trend, and it is predicted that mental disease burden in China will increase to about one fourth of the overall disease burden till 2020.

With the development of the society, people from all walks of life are paying more and more attention to mental health, and they come to realize that mental health is the foundation for social harmony, and is the guarantee for sustainable development of people. However, the development of mental health service in China is still not that sound by now, some data indicates that, according to CIDI/DSM-IV diagnosis standard, mood disorders mainly focusing on anxiety disorder and depression among Chinese adults etc. are relatively serious. Annual illness ratio of substance use disorder and impulse control disorder is $7.0 \%$, among which only a small part of patients have accepted mental treatment. ${ }^{3}$ According to statistics from related foreign data, $10 \%-15 \%$ people need consultancy service, calculating based on this proportion, at least 130 million people in China need

\footnotetext{
22005 World Mental Health Day Theme "Mental and Physical Health Leads to a Happy Life" None - China Health Education - 2005

${ }^{3}$ http://lib.cmc.edu.cn/UpLoadFiles/Article/20074/200704200824... - Internet Data - 2006-07-01
}

consultancy service. There's a rigorous challenge in Chinese mental health service.

\section{FUTURE TENDENCY OF EAP IN CHINA}

Over more than 30 years development, there has been a great change in China's economy, and there's also a huge change in social environment, enterprise organization and production management level. However, with social and economic development, multiple issues have also appeared during the development process. Seeking for economic benefits, damages to environment, interpersonal alienation, increase in pressure, unharmonious living and working rhythms etc. are impacting the crowd's physical and mental health, however, confusions are also brought by people's mind failing to keep pace with the development in economy and society, besides, various mental events and confusions have occurred. Such situation will not only impact an individual's physical and mental health as well as the sense of happiness, and will even impact a family's harmony and happiness or social order and development. For example, bad public security situation in some places will generate more unsafe elements to the society, while most such security events are caused by people's mental recognition at that time, and if such situations are intervened in time and managed in a legal manner, to a certain extent, social security could be improved. At present, Chinese physiology and EAP service are still in the initial stage, while mental consultancy required by the society and the people are in great need, however, these are still not accepted in its form. In such a special time, special attitude plays an important role in EAP's Chinese mode development research.

With respect to today's China, although enterprises have developed to a certain extent, when compared with western countries, there're still lagging and deficiencies in organization management level and employee welfare planning aspects. The application of management in China mainly copy technologies from the west, with few research and application in local places, and there's certain difference in validity and credibility of management when compared with foreign countries. In Chinese traditional concept, basically, organization takes the priority, then employee status and organization's concept, this relates to the thought formed by long history of agricultural cultivation. Low human resource quality and abundant human resource origin, makes humanbased management become a luxury one. Organization seldom adopts human-based management ideology to carry out operational activities. However, for early commencement of western industrial civilization, a set of mature and human-based management tools have been 
summarized during operational activities of the overall organizational structure. This concept has existed in an early period of time when the west recognized that profits generate from human resource (which has also been proved by Marx's theory of surplus value). So the west has spent lots of energy in searching human-based management. Understanding and research on this aspect have stayed on the deed of merely copying western theories and experiences all the time, however, there're still lots of enterprises and human-based management ideologies have not been accepted by now. At present, most enterprises adopting human-based management are mainly organizations with international cooperation businesses and international personnel. Basically, this is used for there's no choice because of rigid demand in organizational culture. There're few forerunners in human-based management field in China.

EAP's concept and related activities have been introduced in China by transnational companies and psychological experts in the earliest time. For early EAP activities in China, some are developed under the cooperation between enterprises and hospitals. But for the expertise mastered by mental physicians in these hospitals are mainly for serious mental diseases, they are not that familiar with enterprise management, so assistance and service provided by them could not solve enterprises' problems in an allround way effectively. At present, in China mainland, most enterprises adopting EAP service or mental consultancy service are mainly branches of some transnational companies in China, while private enterprises or state-owned enterprises are relatively few. Basically, almost no enterprises of middle and small size have ever introduced EAP technology, for most Chinese enterprises, EAP is a new concept, which needs a process to understand.

\section{ANALYSIS ON REAL DEMAND IN MIDDLE AND SMALL-SIZED ENTERPRISES IN CHINA BASED ON EAP VALUE ORIENTATION}

The biggest difference between Chinese and Western culture lies in western personal standard and Chinese ethical standard. Western culture focuses on individualism, while the western pay more attention to themselves, and to the development of personality, so as to express individual's uniqueness. They advocate individuals' freedom, right and independency. Internal family relationship also indicates strong individualism. This mainly lies in that private ownership has deepened into the family, and all family members (such as father, sun, brother and couple etc.) have their own private properties, this has founded a basis for the individuality of each member, while legal relationship and right relationship will be certain to enter the family, and become the most important relationship among all family members. In the enterprise, for personal interests are higher than collective interests, it is required to meet individual interests first. Western management level pay more attention to employees, and hope to make employees enjoy some organizational welfares via solving mental and mood issues for employees, so that they could face work and life in a better manner, while their life quality could also be improved either. How to reduce communication disorders, and obtain the glory of human nature of the world, under today's economic globalization, EAP is another carrier of the best advantages.

Large amounts of practice and theoretic research need EAP workers to make great efforts, for EAP workers, being engaged in such a work is a lofty undertaking, and there're lots of fields to utilize EAP to solve problems.

EAP originates from western countries and prevails in western developed countries. Quite a few successful experiences and industrial standards have been accumulated in international EAP industries. Especially for experiences in Hong Kong, Taiwan, Singapore and Japan etc., for similar culture of the same origin, these possess more reference significance. For EAP's future development in China, except for exploring a road for EAP development with Chinese characteristics, it is still required to carry out lots of communication with foreign counterparts, including communication and cooperation with international EAP associations, so as to develop a Chinese EAP mode in the best manner.

It is required to pay attention to employees and origination structure during EAP's future development in China, via work in three aspects which are namely employees, managers and organizational structure, to realize the harmonious win-win objective between the enterprise and employees.

Under such specific social historic culture and economic development environment in China, there're various enterprise organizations with different ownerships, different scales, development stages as well as employee compositions. They have different demands in EAP. In future, EAP will be greatly used in China, main form of which will be training and consultancy on EAP.

Value Analysis on the Application of EAP Technology in Middle and Small-Sized Enterprises A simple chart is used to indicate value analysis of middle and small-sized enterprises to use EAP technology. 
Value Chart of Chinese Middle and Small-Sized Enterprises' using EAP (Fig. 1)

\begin{tabular}{|c|c|}
\hline Strategic Planning for Organizing EAP & EAP's Strategic Implementation Process Effect \\
\hline 1. Strategic significance for organizing EAP. & 1. Identify EAP's application value. \\
\hline 2. EAP's organizational role and quality analysis planning. & 2. EAP's department implementation and job refinement. \\
\hline 3. Technology planning analysis and design. & 3. Detailed implementation planning content. \\
\hline 4. Mental environment matching strategies. & 4. Carry out correction according to investigation. \\
\hline $\begin{array}{l}\text { 5. Carry out assessment and development on leadership via } \\
\text { combining EAP planning. }\end{array}$ & 5. Work analysis of EAP's linking with the enterprise. \\
\hline 6. Assess successors according to EAP's analysis data. & 7. Work implementation of optimizing organizational structure. \\
\hline 8. Mental evaluation in recruitment and selection. & 8. External recruitment used by EAP in human resource. \\
\hline 9. Mental configuration of organization. & $\begin{array}{l}\text { 9. Inner and outer recruitment implementation under EAP } \\
\text { environment. }\end{array}$ \\
\hline 10. Mental management of enterprise culture. & 10. Macro-utility implementation of EAP. \\
\hline 11. Plan design combining EAP technology. & 11. Establishment of dynamic system adjustment. \\
\hline 12. Organizing mental management basic indications & 12. Determination of indications. \\
\hline $\begin{array}{l}\text { 13. Organizing mental management and treatment } \\
\text { structure. }\end{array}$ & 13. Company treatment structure implementation under EAP plan. \\
\hline $\begin{array}{l}\text { 14. Organizing mental management outsourcing and } \\
\text { service process optimization. }\end{array}$ & 14. Process outsourcing under inner EAP policy planning. \\
\hline 15. Dynamically circulating the above circles. & 16. Dynamically circulating the above circles. \\
\hline
\end{tabular}

\section{CONCLUSIONS}

It has been indicated by large amounts of research and practice that EAP will play an extremely important role in development of the organization and individual. Basically, such management and support mode has been popularized in western countries. One advantage of EAP is to solve all problems likely to be encountered in management in a flexible manner. Using EAP (Employee Assistance Plan) as a starting point, till now, it could be regarded as a practical science formed via combining psychology with multiple cross-sciences such as management and sociology etc., and such science exists in the form of organization consultancy, considering "Win-win between the enterprise and employees, joint realization" as its value orientation. From requirements in scientific management, international perspective, realization of competition intensification, collective characteristics of Chinese people, generation mode of middle and small-sized enterprises in China as well as operation management mode, China is in great need of EAP mode, and such application shall be promoted to the greatest extent.
Realize the localization of EAP, to make it root and sprout, flourish and fructify on the land of China. Serve Chinese enterprises, add strengths to Chinese economy, and provide practicable and professional support to realize a harmonious and rich Chinese outlook with modern civilization elements.

In the near future, EAP (OAP) is certain to prevail in China, and provide consultancy service of the highest quality for China's economic development.

\section{REFERENCES}

[1] Zhu Jianjun The Will of Chinese People and Culture Shanxi People's Publishing House (April, 2008) Edition 1 ;

[2] Daniel Houseman (USA) Philosophy of Economics Shanghai People's Publishing House (March, 2007), Edition 1;

[3] Lang Xianping Thoughts Oriental Publishing Center (Jan., 2006), Edition 1;

[4] Shen Yue Research on Political Economics and Socialist Economy Economic Daily Press (Jul., 2007) Edition 1;

[5] Zhao Ran Employees Assistance Plan Science Publishing House (Jun., 2010) Edition 1;

[6] Wen Yuankai, Zhang Mao China Beauty 50 Beijing Publishing House (Jan., 2010) Edition 1; 